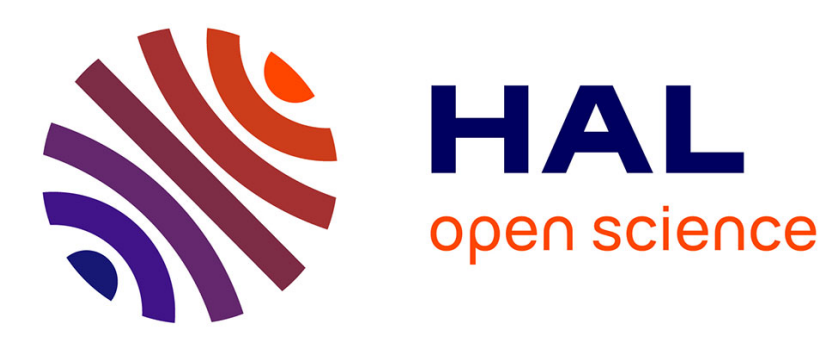

\title{
Has the Golden Rule of Public Finance Made a difference in the UK
}

Jérôme Creel, Paola Veroni, Francesco Saraceno

\section{To cite this version:}

Jérôme Creel, Paola Veroni, Francesco Saraceno. Has the Golden Rule of Public Finance Made a difference in the UK. 2007. hal-00972843

\section{HAL Id: hal-00972843 \\ https://hal-sciencespo.archives-ouvertes.fr/hal-00972843}

Preprint submitted on 3 Apr 2014

HAL is a multi-disciplinary open access archive for the deposit and dissemination of scientific research documents, whether they are published or not. The documents may come from teaching and research institutions in France or abroad, or from public or private research centers.
L'archive ouverte pluridisciplinaire HAL, est destinée au dépôt et à la diffusion de documents scientifiques de niveau recherche, publiés ou non, émanant des établissements d'enseignement et de recherche français ou étrangers, des laboratoires publics ou privés. 


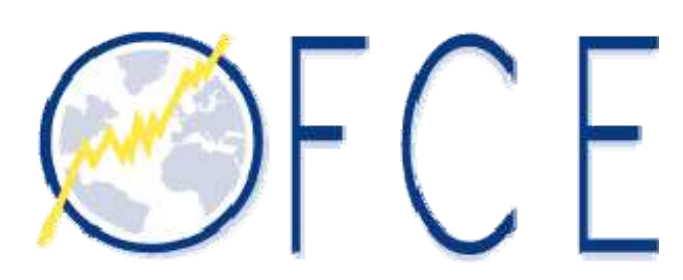

\title{
Document de travail
}

Has the Golden Rule of Public Finance Made a Difference in the UK ?

\author{
$N^{\circ} 2007-13$
}

Avril 2007

Jérôme Creel (OFCE)

jerome.creel@sciences-po.fr

Paola Monperrus-Véroni (OFCE)

paola.veroni@sciences-po.fr

Francesco Saraceno (OFCE)

francesco.saraceno@sciences-po.fr 


\title{
Has the Golden Rule of Public Finance Made a DIFFERENCE IN THE UK?*
}

\author{
Jérôme CREEL (OFCE) \\ Paola MONPERRUS-VERONI (OFCE) \\ Francesco SARACENO (OFCE)
}

APRIL 2007

\begin{abstract}
This paper uses the SVAR methodology to investigate the effects of public investment on growth, and more specifically, the effects of the introduction of a golden rule of public finance. We extend the existing literature by estimating a model of the British economy that takes into account long run factors such as public debt accumulation. We find that in such a long run framework, public investment has a significant and permanently positive effect on GDP growth; this result runs counter to the most recent literature on the topic that was limited to a short run specification. We further find, by comparing different subsamples, that the introduction of the golden rule in 1997 strengthened the positive effect of public investment.
\end{abstract}

Keywords: fiscal policy, golden rule of public finance, Structural VAR, Public Investment, UK Economy

JEL Codes: C32, E60, E63, H60

* We are grateful for the comments from the discussants and the participants at the 8th Banca d'Italia Workshop on Public Finance, Perugia, March 2006, and at Séminaire Hétérodoxie, Université Paris 1 PanthéonSorbonne, January 2007. We also thank Gwenaëlle Poilon for skillful research assistance. The usual disclaimer applies.

- Corresponding author: OFCE, research department, 69, quai d'Orsay, 75340 Paris cedex 07, France, tel. + 331441854 56; fax + 331441854 78, email jerome.creel@sciences-po.fr. 


\title{
Has the Golden Rule of Public finance Made a DIFFERENCE IN THE UK?
}

\begin{abstract}
This paper uses the SVAR methodology to investigate the effects of public investment on growth, and more specifically, the effects of the introduction of a golden rule of public finance. We extend the existing literature by estimating a model of the British economy that takes into account long run factors such as public debt accumulation. We find that in such a long run framework, public investment has a significant and permanently positive effect on GDP growth; this result runs counter to the most recent literature on the topic that was limited to a short run specification. We further find, by comparing different subsamples, that the introduction of the golden rule in 1997 strengthened the positive effect of public investment.
\end{abstract}

Keywords: fiscal policy, golden rule of public finance, Structural VAR, Public Investment, UK Economy

JEL Codes: C32, E60, E63, H60 


\section{Introduction}

The "golden rule of public finance" and the incidence of public investment on economic growth remain a controversial issue. The adoption of this rule by the UK in 1997 stirred a debate, not settled yet, on whether the fiscal framework for the European Union - the Stability and Growth Pact - should be amended to take into account the peculiarity of public investment ${ }^{1}$. This debate has proceeded on the double track of whether public investment is beneficial to economic growth, and whether the golden rule would be able to ensure a sufficient level of public investment without hampering the sustainability of public finances.

Standard textbook analysis emphasises the positive role of public spending on economic growth, at least in the short run. The development of endogenous growth theory has also given considerable importance to public aid and productive government services in fostering innovation, the production of human capital and ultimately, economic growth in the longer run $^{2}$. However, these results depend on the relative weight of contrasting factors like crowding out, externalities, and strategic interactions with monetary policy. Turning towards the empirical literature does not help much, as its results are mixed at best.

Drawing on the UK recent experience makes it possible to disentangle the different factors which influence economic growth as well as to check whether the recent increase in public investment has had a positive impact on it. Indeed, since the implementation of the 'Code for Fiscal Stability', public investment has increased from the low $0.75 \%$ of GDP it had reached in the fourth quarter of 1996 , to $2.5 \%$ in 2005 .

This paper develops a comparative method to analyze the regime change experienced in the UK with the introduction of the golden rule. We build on the increasingly popular literature on structural VARs that originally developed in the field of monetary theory and has finally been applied to fiscal policy since the seminal papers of Blanchard and Perotti (2002) and Perotti (2004).

In contrast with the existing literature however, we extend the underlying model and take into account a long time-horizon. This seems a natural and necessary extension when discussing a typically long run phenomenon like investment; moreover, in a longer time horizon, the dynamics of public debt and its sustainability cannot be disregarded and have therefore to be dealt with. Nevertheless, to our knowledge this long run perspective has never been adopted in the literature. In this paper we show that taking into account the long run dramatically changes the results with respect to the paper of Perotti (2004) that we use as a benchmark: a positive and persistent effect of public investment on economic growth robustly emerges in our specification. We further find that this effect became more robust since the introduction of the golden rule in 1997, thus offering indirect empirical support to this institutional framework.

\footnotetext{
${ }^{1}$ The pros were, e.g., Blanchard and Giavazzi (2003) and Fitoussi and Creel (2002); whereas the cons were, e.g., Buti, Eijjfinger and Franco (2003).

${ }^{2}$ See, e.g., Barro and Sala-I-Martin, (1995); Aghion and Howitt, (1998).
} 
The paper is structured as follows: the next section briefly reviews the 'Code for Fiscal Stability' and the consequent debate on the golden rule; a short summary of the recent literature on the effects of public investment on growth is also sketched. Then, section 3 details the methodology, describing the SVAR identification procedure. Different identification procedures are mapped to different institutional settings. Section 4 presents the estimation results. Robustness tests are discussed in section 5. Finally, section 6 concludes.

\section{The "Golden Rule of Public Finance"}

The 'Code for fiscal stability', laid before the UK Parliament under section 155 of the Finance Act 1998, was meant to "improve the conduct of fiscal policy by specifying the principles that shall guide the formulation and implementation of fiscal policy"3. Among these principles are "stability in the fiscal policy-making process and in the way fiscal policy impacts on the economy; (...) fairness, including between generations; and efficiency in the design and implementation of fiscal policy and in managing both sides of the public sector balance sheet." The government has also specified two key fiscal rules in accordance with these principles: the 'golden rule' and the 'sustainable investment rule'.

The golden rule states that, over the cycle, government borrowing should not exceed net government capital formation; hence, current spending should be financed by current receipts. Indeed, the UK budget incorporates a medium-run target for the net-of-public investment deficit, where the medium-run corresponds to a cycle. Over this cycle, this deficit should be balanced. The golden rule thus allows the UK to spread the cost of durables over the financial years in which they will be in use, and the burden of capital formation over the generations of taxpayers benefiting from it ${ }^{4}$. The golden rule is associated with a "sustainable investment rule" in order to prevent any overinvestment and to limit net public debt below $40 \%$ of GDP: "public sector net debt as a proportion of GDP will be held over the economic cycle at a stable and prudent level" (HM Treasury, 2002).

Since 1998 then the UK has adopted a double budget approach; the budget is split into a balanced current account and a deficit-financed capital account. A quick look at the data (figure 1) shows the impact of the new fiscal strategy on government gross fixed capital formation (GFCF). After a steep fall from 2\% of GDP to below 1\% of GDP between 1994 and 1997, government GFCF has almost continuously increased since 1998, exceeding again $2 \%$ of GDP in 2005. Two elements are worth mentioning. First, the present ratio is still largely below its value of the early Seventies and there may still be some scope for further increases. Second, the efficiency of the new 'Code' and of the accompanying golden rule can be grossly assessed by a comparison between the fiscal stance and the ratio of government

\footnotetext{
${ }^{3}$ Quotations in this section are from the 'Code for fiscal stability', unless otherwise stated.

4 Though the welfare benefits of boosting public investment may be unevenly distributed across generations - public investment should increase private capital formation and wages, but the latter rise only gradually whereas the former is in the hands of the "elderly" -, Heijdra and Meijdam (2002) show that financing some part of public investment with public bonds increases equality across generations. A "golden rule" is thus theoretically welfare-improving.
} 
GFCF on GDP. In the past, fiscal restrictions were negatively correlated with this ratio: the positive trend of the primary balance (in percent of GDP) between 1976 and 1988 was concomitant with a decrease in government GFCF from 2.5 to $1 \%$ of GDP. This negative correlation was also clearly apparent between 1993 and 1997. Fiscal restrictions could thus be thought of as provoking a fall in public investment. Since 1998 however, the correlation has vanished: notwithstanding the swing in the fiscal stance, government GFCF has never stopped increasing. Public investment does no longer seem to be a residual in the implementation of fiscal policy.

\section{[INSERT FIGURE 1]}

So far, assessments of the UK golden rule have been rare. From a general point of view Balassone and Franco (2000) are rather critical on the enforcement of this institutional arrangement. They recall that the definition of "public investment" in national account statistics includes transactions that lead to changes in the stock of physical capital (like the construction of infrastructures or the purchase of computer hardware), but excludes large amounts of expenditures related to the accumulation of human capital, like training or R\&D. Hence, they argue that a golden rule may only result in a bias in favour of physical assets, at the expense of health and education expenditures. More in general, the vagueness of the concept of "public investment" may lead to dangerous practices of creative accounting, whose aim would be to cover lack of fiscal discipline. Finally, the golden rule promotes public capital, though it is overall capital from the public and private sectors that should be prompted. Thus, the authors conclude that, as long as public capital crowds out private investment (a claim that nevertheless seem to be contradicted by the data: see e.g. Aschauer, 1989b, and EC, 2003, table III. $2^{5}$ ), no positive effect can be expected.

Buiter (2001) argues along similar lines. While acknowledging the necessity to distinguish between current and capital spending in the budget, he warns against the possible excessive surge in public debt and also insists on the constraining nature of the fiscal framework if a non expected shock occurred in the UK. Finally, he doubts that the golden rule would be an efficient tool to enhance economic growth as some public investment projects do not yield direct cash returns and will have to be financed by future distortionary taxes or future cuts in current spending. Sawyer (2006) considered the effects that fiscal policy may have produced on UK macroeconomic performance. He concludes that "the close-toachievement of the golden rule owes much to the surpluses generated in the late 1990s by the investment boom and lower savings, to reduction in nominal interest rates lowering interest payments on public debt, to use of the Private Finance Initiative ${ }^{6}$ and to the re-dating of the cycle.” (p. 10).

\footnotetext{
${ }^{5}$ Interestingly, the one country for which EC seems to find a negative correlation between public and private investment (crowding out) is the UK. Nevertheless, they argue that this might result from a coincidence: the privatisation process would have decreased public investment while increasing "to a certain extent" investment in the private sector.

${ }^{6}$ The Private Finance Initiative (PFI) is a public-private partnership aiming at delivering high quality public services. Sawyer argues that the PFI will provoke a sharp deterioration in the future debt position of the UK
} 
The empirical literature on "public capital productivity" is extremely vast. Tables 1a and 1b report some major contributions on the impact of public capital or public investment on economic growth, applied to a wide range of countries and using different methodologies. What appears clearly is the opposition between two major strands of the literature. In particular, the VAR literature seems to find no or little effect of public investment on growth (table 1b) whereas estimations using a production function approach (table 1a) generally conclude that public capital does impinge on economic growth. Exceptions are Ratner (1983), Garcia-Mila and McGuire (1992) and Evans and Karras (1994). Recent estimates by Bleaney et al. (2001) and Gong et al. (2004) point to significant impacts of public capital spending on economic growth, except for the former if distortionary taxes are also increased.

Table 1a. A parsimonious survey on the contribution of public capital to economic growth

\begin{tabular}{|l|l|}
\hline \multicolumn{1}{|c|}{ Methodology } & \multicolumn{1}{c|}{ Contribution of public capital to economic growth } \\
\hline Production-function approach & \\
\hline Ratner (1983) & $=0.056$ (US data) \\
\hline Aschauer (1989a) & $\begin{array}{l}{[0.29, \quad 0.56] \text { depending on assumptions about }} \\
\text { productivity (US data) }\end{array}$ \\
\hline Ram and Ramsey (1989) & $=0.24$ (US data) \\
\hline Garcia-Mila and McGuire (1992) & $=0.05$ (48 US states) \\
\hline Eisner (1994) & $=0.27$ (US data) \\
\hline Sturm and De Haan (1995) & $=0.41$ (US data) \\
\hline Vijverberg et al. (1997) & $=0.48$ (US data) \\
\hline Evans and Karras (1994) & fragile and generally not significant (7 OECD countries) \\
\hline Dessus and Herrera (1996) & $=0.26$ (panel, 28 countries) \\
\hline Merriman (1990) & $=0.58$ (9 Japanese regions) \\
\hline Berndt and Hansson (1991) & $=0.68$ (Swedish data) \\
\hline Bajo-Rubio et al. (1993) & $=0.19$ (Spanish data) \\
\hline Otto and Voss (1994) & $=0.38$ (Australian data) \\
\hline Wylie (1996) & $=0.51$ (Canadian data) \\
\hline Gong et al. (2004) & $=0.50$ (US data) \\
& $=0.29$ (German data) \\
\hline Estimations including the budget composition & \\
\hline $\begin{array}{l}\text { Kneller, Bleaney and Gemmel (1999) } \\
\text { Bleaney, Gemmel and Kneller (2001) }\end{array}$ & $=0.29$ (panel, OECD countries) \\
& $=-0.45$ (elasticity to distortionary taxation) \\
\hline
\end{tabular}

\section{Specification and identifications}

We have endeavoured to assess the impact of public investment on GDP growth in the UK using the SVAR methodology originally applied to fiscal policy by Blanchard and Perotti (2002) who disentangled the effects of automatic and discretionary fiscal policies in the US. This choice may seem at odds with the results summarized in table $\mathbf{1 b}$, that shows a 
substantial lack of capacity of these models to obtain conclusive results on the effects of fiscal policy. It is justified however for a number of reasons. First, the VAR methodology seems the most appropriate to identify the specific causes of economic growth, to disentangle the effects of the policy mix, and to study the responses to shocks, as has been shown by an important strand of the literature on monetary policy (see e.g. Christiano, Eichenbaum and Evans, 1999). Second, although multiplier effects had long been thought to be weak in the literature, this recent SVAR methodology has shown that these effects were substantial; consequently, it has renewed interest for fiscal policy and for the effects of its components (mainly current expenditure and public investment).

Table 1b. VAR studies

\begin{tabular}{|c|c|c|c|}
\hline Study & Data & Variables & Conclusions \\
\hline Clarida (1993) & $\begin{array}{l}\text { USA, France, Germany, } \\
\text { United Kingdom: 1964- } \\
1989\end{array}$ & $\begin{array}{l}\text { Multifactor productivity, } \\
\text { public capital stock }\end{array}$ & $\begin{array}{l}\text { MFP and public capital } \\
\text { are cointegrated but } \\
\text { direction of causality is } \\
\text { unclear }\end{array}$ \\
\hline $\begin{array}{l}\text { McMillin and Smyth } \\
\text { (1994) }\end{array}$ & USA: 1952-1990 & $\begin{array}{l}\text { Hours of work per unit of } \\
\text { capital; relative price of } \\
\text { energy; ratio public capital to } \\
\text { private capital; inflation }\end{array}$ & $\begin{array}{l}\text { No significant effect of } \\
\text { public capital }\end{array}$ \\
\hline Otto and Voss (1996) & Australia: 1959-1982 & $\begin{array}{l}\text { Private sector GDP; private } \\
\text { capital stock; public capital } \\
\text { stock; number of working } \\
\text { hours }\end{array}$ & $\begin{array}{l}\text { No significant relation } \\
\text { between public capital } \\
\text { and output }\end{array}$ \\
\hline $\begin{array}{l}\text { Sturm, Jacobs and } \\
\text { Groote (1999) }\end{array}$ & Netherlands: 1863-1913 & $\begin{array}{l}\text { Private sector GDP; private } \\
\text { capital stock; public capital } \\
\text { stock; private labor }\end{array}$ & $\begin{array}{l}\text { Public infrastructure } \\
\text { Granger-causes output }\end{array}$ \\
\hline Ligthart (2000) & Portugal : 1965-1995 & $\begin{array}{l}\text { GDP; private capital stock; } \\
\text { public capital stock; private } \\
\text { labor }\end{array}$ & $\begin{array}{l}\text { Public capital Granger- } \\
\text { causes output }\end{array}$ \\
\hline Otto and Voss (2002) & $\begin{array}{l}\text { USA: 1951-1997 } \\
\text { Canada:1951-1996 }\end{array}$ & $\begin{array}{l}\text { GDP, relative price of public } \\
\text { and private investment goods, } \\
\text { real interest rate and shares of } \\
\text { private and public investment } \\
\text { in output }\end{array}$ & $\begin{array}{l}\text { Public investment crowds } \\
\text { out private investment in } \\
\text { both countries }\end{array}$ \\
\hline
\end{tabular}

But the third and probably most important reason for our choice lies in our educated guess on the reasons why the VAR literature on public investment has yielded inconclusive results. We believe that the VAR exercises so far have neglected a crucial factor: the time dimension. Public capital and public investment do take time to produce their effects; In turn, taking a long run perspective in the analysis of fiscal policy requires that the dynamics of public debt be taken explicitly into account in the analysis.

For all these reasons in what follows we use a variant of Blanchard and Perotti's (2002) empirical methodology, dividing public spending in investment and consumption, but also 
encompassing debt dynamics and monetary policy in order to disentangle the different policy transmission mechanisms in a long run framework.

\subsection{The theoretical model}

The background theoretical model that we use to impose coherence to our identification procedure is a variant of the closed economy model of Leith and Wren-Lewis (2000) and Creel and Sterdyniak (2002), which in turn extended Blanchard (1985)'s perpetual youth model to include fiscal and monetary interactions.

The model is in reduced form. The first equation is an aggregate demand relationship (all variables are real; fiscal variables are expressed in percent of GDP):

$$
y_{t}=c y_{t-1}+(1-c)\left[-\tau_{t}-\delta r_{t}+\varphi b_{t}+g_{c, t}+g_{i, t}\right]
$$

where $y$ is output, $\tau$ tax revenues, $r$ the real interest rate, public expenditure is the sum of public investment and current outlays $g_{i}+g_{c}$, and $b$ is public debt; real public debt affects demand positively (due to a wealth effect) ${ }^{7}$, and the real interest rate has a negative influence on demand.

Aggregate supply is a standard Lucas-supply curve relating inflation to the output gap:

$$
\pi_{t}=E_{t+1} \pi_{t}+v\left(y_{t}-\bar{y}\right)
$$

where $\mathrm{E}$ is the expectation operator, and upper bars denote steady-state variables.

Real debt cumulates according to a standard law of motion:

$$
b_{t}=b_{t-1}\left(1+r_{t}\right)-\tau_{t}+g_{i, t}+g_{c, t}
$$

Finally, two equations define the reaction functions of fiscal and monetary authorities:

$$
\tau_{t}=\bar{\tau}+h\left(b_{t}-\bar{b}\right)
$$

and

$$
r_{t}=\bar{r}+\mu\left(\pi_{t}-\bar{\pi}\right)+\theta(y-\bar{y})
$$

Equation (4) states that the fiscal authority reacts to deviations of debt from its steady state value. This equation assumes a "spend \& tax" framework but it could be replaced easily by a "tax $\&$ spend" framework whereby public spending would be more or less reduced, depending on the value of $h$, if debt grew above its steady state value. Equation (5) is a standard Taylor rule relation if $\mu$ is positive (hence an inflationary shock would provoke a rise in the real interest rate).

The stability conditions for this model are derived in the appendix; stability requires coordination of fiscal and monetary authorities, either on a tough strategy or on a mild one. If the central bank is inflation-averse ( $\mu$ is positive), the steady state is locally stable in so far as

\footnotetext{
${ }^{7}$ This is one important conclusion of Blanchard (1985) model with finitely-lived agents.
} 
fiscal policy dampens the growth of public debt and ensures sustainability. In this situation, fiscal policy must accommodate monetary policy and its impact on interest payments. If the central bank is not inflation-averse ( $\mu$ is negative), the reverse allocation of policy instruments is required: monetary policy must accommodate fiscal policy and its impact on inflation.

\subsection{The statistical model}

To evaluate the policy interactions highlighted by the theoretical model, we build a variant of the structural VAR model elaborated by Blanchard and Perotti (2002). The model is extended to include public debt, and to distinguish between government consumption and government investment (net of interest payments). Let $g_{c}, g_{i}, \tau, b, \pi, r$ and $y$ denote respectively the real values of government consumption (hereafter current outlays), government investment (hereafter public investment), net taxes (tax revenues less transfers to households and businesses), public debt, inflation, the real interest rate and GDP, all stated in logs except inflation and interest rates. Public finance data are expressed in percent of GDP.

Let $\mathbf{Y}_{\mathbf{t}}$ and $\mathbf{U}_{\mathbf{t}}$ denote the vector of endogenous variables and of reduced-form residuals of the VAR, respectively. The reduced form VAR can be written:

$$
\mathbf{Y}_{t}=A(L) Y_{t-1}+U_{t}
$$

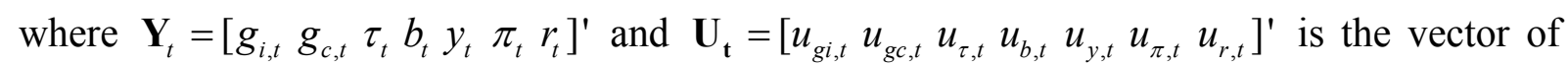
residuals. $\mathbf{A}(\mathrm{L})$ is the $\mathrm{L}$-quarter lag operator.

The residuals of the canonical VAR are uninformative on the response of endogenous variables to shocks. In order to obtain response functions which are meaningful for the analysis of economic policy, we need to isolate structural shocks. Thus, while the canonical residual of, say, the tax rate collects information on all the unexpected movements of the variable, the corresponding structural residual is obtained by eliminating all instantaneous feedback mechanisms (either automatic or discretionary) triggered by changes in the other endogenous variables. Finally, the structural residual will be interpreted as an autonomous shock (or structural shock), whose effects on the other variables can be examined by means of impulse response functions (IRF).

The identification methodology consists in isolating structural shocks by a three-step procedure. We begin by writing the reduced form canonical residuals of the three fiscal policy variables as linear combinations of the structural, automatic and discretionary components mentioned above:

$$
\begin{aligned}
& u_{g i, t}=\alpha_{g i, y} u_{y, t}+\alpha_{g i, \pi} u_{\pi, t}+\beta_{g i, g c} e_{g c, t}+\beta_{g i, \tau} e_{\tau, t}+e_{g i, t} ; \\
& u_{g c, t}=\alpha_{g c, y} u_{y, t}+\alpha_{g c, \pi} u_{\pi, t}+\beta_{g c, g i} e_{g i, t}+\beta_{g c, \tau} e_{\tau, t}+e_{g c, t} ; \\
& u_{\tau, t}=\alpha_{\tau, y} u_{y, t}+\alpha_{\tau, \pi} u_{\pi, t}+\beta_{\tau, g c} e_{g c, t}+\beta_{\tau, g i} e_{g i, t}+e_{\tau, t} ;
\end{aligned}
$$

where $e_{g c, t}, e_{g i, t}$ and $e_{\tau, t}$ are the structural shocks to the three fiscal policy variables. The first two terms on the RHS of each equation in block (6) capture the automatic responses of fiscal policy to a change in GDP or in inflation (the elasticities, denoted with $\alpha^{\prime} s$ ). The following 
two terms (the $\beta^{\prime} s$ ) capture the discretionary responses to a structural shock on another policy variable, whereas the last term captures the structural policy shock. Debt has a similar equation:

$$
u_{b, t}=\alpha_{b, \pi} u_{\pi, t}+\alpha_{b, r} u_{r, t}+\beta_{b, g i} e_{g i, t}+\beta_{b, g c} e_{g c, t}+\beta_{b, \tau} e_{\tau, t}+e_{b, t}
$$

where we add also a term describing the elasticity with respect to the real interest rate.

The system (6-7) is completed by the equations relating the canonical residual on the remaining variables with their structural shocks. This is done on the basis of the theoretical relationships described above (equations 1 to 5):

$$
\begin{aligned}
& u_{y, t}=\gamma_{y, g i} u_{g i, t}+\gamma_{y, g c} u_{g c, t}+\gamma_{y, \tau} u_{\tau, t}+\gamma_{y, b} u_{b, t}+\gamma_{y, r} u_{r, t}+e_{y, t} \\
& u_{\pi, t}=\gamma_{\pi, y} u_{y, t}+e_{\pi, t} \\
& u_{r, t}=\gamma_{r, y} u_{y, t}+\gamma_{r, \pi} u_{\pi, t}+e_{r, t}
\end{aligned}
$$

In system (8), the $\gamma^{\prime} s$ refer to the systematic responses of non-policy variables to endogenous variables.

Formally, identifying the structural shocks requires the construction of a matrix $\mathbf{P}$ such that $\mathbf{U}_{\mathbf{t}}=\mathbf{P} \boldsymbol{\Omega}_{\mathbf{t}}$ where $\boldsymbol{\Omega}_{\mathbf{t}}$ is the vector of structural shocks which are independent and identically distributed with covariance matrix equal to the identity one. In the vein of Blanchard and Perotti (2002), we write $\mathbf{M}_{1} \mathbf{U}_{\mathbf{t}}=\mathbf{M}_{\mathbf{2}} \boldsymbol{\Omega}_{\mathbf{t}}$ where the matrix $\mathbf{M}_{\mathbf{1}}$ links contemporaneously the reduced form innovations while $\mathbf{M}_{2}$ describes how structural shocks affect the endogenous variables of the VAR. The identification procedure then consists in imposing constraints on the elements of $\mathbf{M}_{\mathbf{1}}$ and $\mathbf{M}_{\mathbf{2}}$ that allow to write $\boldsymbol{\Omega}_{\mathbf{t}}=\mathbf{M}_{\mathbf{2}}{ }^{-1} \mathbf{M}_{\mathbf{1}} \mathbf{U}_{\mathbf{t}}$.

The constraints are of three economic kinds. First, we rely on institutional information about tax, transfer and spending programs to construct some of the elasticity parameters $\alpha_{i, y}, \forall i=g c, g i, \tau, b$. For instance, regarding taxes, some do depend on contemporaneous GDP (VAT is an example) whereas some others do not as their base is time-delayed (the UK corporation tax return needs to be paid with the Inland Revenue, now HM Revenue and Customs, 12 months after the end of the relevant accounting period). Thus the elasticity with respect to contemporaneous GDP is positive for VAT and zero for the corporate tax. Furthermore, all fiscal and tax variables are net of interest payments and receipts; hence they do not depend on the interest rate. Finally in so far as public investment is considered, it is not legitimate to assume an instantaneous impact of GDP; we set: $\alpha_{g i, y}=0$. The remaining elasticities $\left(\alpha_{\tau, y}, \alpha_{g c, y}, \alpha_{g i, \pi}, \alpha_{g c, \pi}, \alpha_{\tau, \pi}, \alpha_{b, \pi}, \alpha_{b, r}\right)$ were computed as the estimation of the log change of the variable on the contemporary log change of either GDP, or inflation, or the interest rate ${ }^{8}$.

\footnotetext{
${ }^{8}$ Two other computation methodologies could have been implemented. First, taking all taxes into account (from income to social contributions), one could compute a weighted-average of tax elasticities where weights would depend on the respective contribution of taxes to tax revenues. Second, like in Blanchard and Perotti, (2002), overall tax elasticity to GDP could be a weighted average of the product of the elasticity of each tax to its
} 
The quarterly time structure of the data allows us to fix also the systematic responses equal to zero (there are no $\gamma^{\prime} s$ in system 6 and equation 7) since economic policy reactions to shocks may be safely assumed not to occur within the quarter.

After this first step, canonical residuals are corrected for economic growth and inflation variations, in order to extract the respective discretionary parts of fiscal and tax variables. We can consequently define the cyclically-adjusted fiscal shocks as the residual net of the effect of output and inflation variation:

$$
\begin{aligned}
& u_{g i, t}^{C A} \equiv u_{g i, t}-\alpha_{g i, \pi} u_{\pi, t}=\beta_{g i, g c} e_{g c, t}+\beta_{g i, \tau} e_{\tau, t}+e_{g i, t} \\
& u_{g c, t}^{C A} \equiv u_{g c, t}-\alpha_{g c, y} u_{y, t}-\alpha_{g c, \pi} u_{\pi, t}=\beta_{g c, g i} e_{g i, t}+\beta_{g c, \tau} e_{\tau, t}+e_{g c, t} \\
& u_{\tau, t}^{C A} \equiv u_{\tau, t}-\alpha_{\tau, y} u_{y, t}-\alpha_{\tau, \pi} u_{\pi, t}=\beta_{\tau, g c} e_{g c, t}+\beta_{\tau, g i} e_{g i, t}+e_{\tau, t} \\
& u_{b, t}^{C A} \equiv u_{b, t}-\alpha_{b, \pi} u_{\pi, t}-\alpha_{b, r} u_{r, t}=\beta_{b, g i} e_{g i, t}+\beta_{b, g c} e_{g c, t}+\beta_{b, \tau} e_{\tau, t}+e_{b, t},
\end{aligned}
$$

where we used systems (6), (7) and (8), to write the second equality of each equation.

The second step imposes constraints based on assumptions on the causation between the different policy variables in the VAR model. There is no a priori reason to favour one ordering over the others. However, one can rely on economic theories and empirical findings to gauge the relationships between the three policy variables under study. Concerning taxes and spending, two theories compete: the "Spend \& Tax" and the "Tax \& Spend" public finance frameworks (see Musgrave, 1966), depending on which variable is constrained by the other when designing policy action. Within the VAR model, a first case arises where public expenditures are left free to affect taxes but not vice versa $\left(\beta_{g c, \tau}=\beta_{g i, \tau}=0\right)$. In the second case, the opposite happens $\left(\beta_{\tau, g c}=\beta_{\tau, g i}=0\right)$.

Concerning spending decisions, we have two further cases. First, government consumption may come first, and public investment adapts to comply with external constraints (i.e., $\beta_{g i, g c}=0$ and $\beta_{g c, g i}$ is estimated). This corresponds to the description by Balassone and Franco (2000) of the process towards the Euro: compliance with the Maastricht deficit limit in the 1990s was shown to have provoked a sharp reduction in public investment vis-à-vis public consumption in Europe ${ }^{9}$. Alternatively, government investment may be determined independently, while government consumption adapts (i.e., $\beta_{g c, g i}=0$ and $\beta_{g i, g c}$ is estimated). This corresponds to the spirit of the golden rule of public finance: the constraint on public expenditure would hinge mostly on government consumption, hence leaving some margins for manoeuvre for public investment. The four policy cases are summarised in table 2.

own base and the elasticity of its tax base to GDP. The methodology which was preferred in this paper is the simplest to perform. Robustness checks of our results with respect to the elasticity values are at any rate presented in the last section of the paper.

${ }^{9}$ The example of Portugal, which reduced investment substantially after breaching the Pact in 2001, shows that the problem remains. 
Table 2. Ordering

\begin{tabular}{|c|c|c|}
\hline & $\begin{array}{c}\text { Spend \& Tax } \\
\text { [I] }\end{array}$ & $\begin{array}{c}\text { Tax \& Spend } \\
\text { [II] }\end{array}$ \\
\hline [a] $g_{i}$ before $g_{c}$ & $\begin{array}{l}\beta_{g c, \tau}=\beta_{g i, \tau}=0 \\
\beta_{g i, g c}=0\end{array}$ & $\begin{array}{l}\beta_{\tau, g c}=\beta_{\tau, g i}=0 \\
\beta_{g i, g c}=0\end{array}$ \\
\hline [b] $g_{c}$ before $g_{i}$ & $\begin{array}{l}\beta_{g c, \tau}=\beta_{g i, \tau}=0 \\
\beta_{g c, g i}=0\end{array}$ & $\begin{array}{l}\beta_{\tau, g c}=\beta_{\tau, g i}=0 \\
\beta_{g c, g i}=0\end{array}$ \\
\hline
\end{tabular}

Because we are mostly concerned with the effects of public spending shocks on the economy, we will focus on the "Spend \& Tax" case (coherently with equation 4 above), and analyse it with different policy priorities between the two expenditure items: either case [I.a] or case [I.b]. Substituting the associated values for the $\beta$ 's in system (9) enables to identify the first structural shock with the related cyclically-adjusted canonical shock

In the estimation procedure, we proceed sequentially: using ordinary-least squares, the second structural shock ( $e_{g i, t}$ and $e_{g c, t}$ in cases [I.a] and [I.b] respectively) is identified as the residual of the regression of the related cyclically-adjusted canonical shock on the structural shock of the previously ordered policy variable. Having identified $e_{g i, t}$ and $e_{g c, t}$, we can estimate $\beta_{\tau, g c}$ and $\beta_{\tau, g i}$ and identify $e_{\tau, t}$. Finally, with $e_{g i, t}, e_{g c, t}$ and $e_{\tau, t}$, we can estimate $\beta_{b, g i}, \beta_{b, g c}$ and $\beta_{b, \tau}$ and identify $e_{b, t}$.

The third set of constraints is related to the estimation of GDP, inflation and the real interest rate in the VAR model. By construction, $e_{g c, t}, e_{g i, t}, e_{\tau, t}$ and $e_{b, t}$ are not correlated with GDP, inflation and the real interest rate. Thus, we can use them as instruments to estimate the $\gamma$ parameters in the first equation of system (8).

This first equation is estimated in a two-step procedure. $e_{g i, t}, e_{g c, t}, e_{\tau, t}, e_{b, t}$ are used as instruments to estimate by OLS the first four parameters of this equation where the term in interest rate, $\gamma_{y r}$, is set equal to zero :

$$
u_{y, t}^{C A} \equiv u_{y, t}-\left(\gamma_{y, g i} u_{g i, t}+\gamma_{y, g c} u_{g c, t}+\gamma_{y, \tau} u_{\tau, t}+\gamma_{y, b} u_{b, t}\right)=\gamma_{y, r} u_{r, t}+e_{y, t} .
$$

Then, $\gamma_{y, r}$ is estimated separately and $e_{y, t}$ is identified.

The $\gamma$ parameter in the second equation of system (8) is estimated taking the structural shock on GDP as an instrument; and the $\gamma$ parameters in the last equation of system (8) are estimated taking the structural shocks, respectively on GDP and inflation as instruments for the unexpected changes in the endogenous variables.

Thus, we are able to determine all coefficients in 7-order each $\mathbf{M}_{\mathbf{1}}$ and $\mathbf{M}_{\mathbf{2}}$ matrices, then all those in 7-order P-matrix. We have fixed 14 ' 1 ' and 60 ' 0 ' (of which $3 \beta$ ); we have 
computed 9 ' $\alpha$ ' and we have estimated $6^{\prime} \beta$ ' and 9 ' $\gamma$ '. These 98 coefficients correspond exactly to the elements in $\mathbf{M}_{\mathbf{1}}$ and $\mathbf{M}_{\mathbf{2}}$ : the matrix $\mathbf{P}$ is just identified.

\subsection{Data and elasticities}

We used quarterly data for the UK from the OECD, ranging from 1972:1 to 2005:4. Contrary to the data available from the UK Central Statistical Office, series are seasonally adjusted. Real series (GDP, tax revenues, current outlays, public investment, and public debt) have been deflated by the GDP deflator.

Inflation $(\pi)$ is computed from the consumer price index. Public debt $(b)$ is defined as end-of-year net financial government liabilities. Tax revenues $(\tau)$ are the difference between government's total receipts and transfers. The latter are defined as the sum of social benefits other than in-kind, interest payments, property income paid by government and other current and capital transfers paid including acquisitions less disposals of non-produced non-financial assets which are excluded from investment. The variable public investment $\left(g_{i}\right)$ is government gross fixed capital formation (GFCF). The variable current outlays $\left(g_{c}\right)$ corresponds to total public expenditures in goods and services, excluding GFCF; in other words, it corresponds to total government final consumption, i.e. the sum of wage consumption expenditure, social transfers in kind and subsidies. The fiscal variables $g_{c}, g_{i}, \tau$ and $b$ are all expressed in percent of GDP.

The values of elasticities are reported in table 3. As expected, current outlays and tax revenues increase contemporaneously at a slower pace than GDP, so that their ratios on GDP decrease. Inflation contemporaneously increases, though only marginally, the ratio of public investment to GDP, whereas the ratios of current outlays and tax receipts on GDP do not react contemporaneously to inflation. A 1-percent change of inflation reduces the share of public debt to GDP by $0.27 \%$, while the interest rate increases it by around $0.07 \%$. These computed elasticities are consistent respectively with the share of indexed public sector debt (it was equal to $23.3 \%$ of total public sector debt at the end of 2004) and with the share of public sector debt issued at a variable interest rate (HM Treasury bills represented $6.8 \%$ of total public sector debt at the end of 2004).

Table 3. Elasticities

\begin{tabular}{ccccccc}
\hline \hline$\alpha_{g c, y}$ & $\alpha_{\tau, y}$ & $\alpha_{g i, \pi}$ & $\alpha_{g c, \pi}$ & $\alpha_{\tau, \pi}$ & $\alpha_{b, r}$ & $\alpha_{b, \pi}$ \\
-0.734 & -0.301 & 0.001 & $-5.72 \mathrm{e}-05$ & $3.48 \mathrm{e}-04$ & 0.071 & -0.270 \\
\hline \hline
\end{tabular}

Most series in our sample are integrated of order one according to ADF tests. Johansen cointegration tests indicate the presence of three cointegration relations but only one out of three is economically consistent: this relation links public debt and fiscal policy (respectively, expenditures and receipts). This accounting relationship is already incorporated in the VAR model and Johansen cointegration test thus legitimates its introduction in the model. The 
absence of other cointegration relations confirms the appropriateness of the strategy suggested by Sims, Stock and Watson (1990) to estimate a VAR in levels despite the integrated series. By means of VAR lag exclusion Wald test, we chose 5 lags for the VAR model.

\section{Results}

The two shocks we consider are first, a shock to public investment; second, a shock to current outlays, each equal to 1 percentage point of GDP decreasing along an AR process.

Figure 2 displays the responses of the 7 endogenous variables to the two different shocks. The figures also display the two symmetric one-standard error bands computed by bootstrapping, as in Stock and Watson (2001). The samples we consider are 1972:1-2005:4 and 1972:1-1997:4, the latter excluding the years over which the 'Code for Fiscal Stability' has been implemented.

The main result of our analysis is at odds with the existing literature (e.g., Perotti, 2004) as regards the impact of public investment on GDP. The shock immediately produces an increase in GDP; this may be related to growth accounting. In the medium run (one year), GDP is negatively affected and then, after one more year, GDP increases again, persistently this time. Although the decrease in GDP in the medium run may be attributed to adjustment delays, it may also be due to higher inflation, through disturbances to households and firms' behaviours.

Nevertheless, the crucial aspect in which we depart from the existing literature is definitely the positive impact of public investment on GDP in the long-run. In our setting, which explicitly takes into account debt and long term public finance issues, the whole evolution of GDP after the shock is statistically significant and the positive impact appearing after around two years is long-lasting.

\section{[INSERT FIGURE 2]}

Current outlays initially respond positively to the investment shock: with growing public investment, civil servants would negotiate higher wages and/or higher public employment whereas public enterprises would ask for higher subsidies ${ }^{10}$; nevertheless this effect is temporary, and in the long run the response of current outlays finally returns towards the initial steady state.

The response of tax receipts is a mirror of the effect on GDP, but it is not significantly different from zero. Debt, on the other hand, initially increases. This increase is temporary: as the positive effect on GDP starts becoming significant, the debt ratio progressively returns towards its steady state value. In some sense, thus, public investment "pays for itself".

The expected and actual short run increase of inflation is matched by a loosening of monetary policy: the nominal short run interest rate does not grow as much as inflation and

\footnotetext{
${ }^{10}$ This is generally called "hijacking of expenditure for the specific benefit of special pressure groups" (see Afonso, Schuknecht and Tanzi, 2006, for a survey on conceptual issues related to the efficiency of public expenditures).
} 
one obtains a decrease of the real interest rate. These effects are short lived, and both variables go back to their respective steady states already in the medium run.

To sum up, the shock on public investment has undesired effects in the short run, such as high debt and inflation. These effects nevertheless vanish in the long run, when the only variable affected in a permanent way is GDP. The result of our analysis is then clear: Public investment does not produce imbalances but only higher economic growth.

After the shock on current outlays, on the one hand, one can observe that the dynamic response of the system is quite similar to the case of a shock on public investment, and that the shock has a permanent effect on GDP. On the other hand, if one observes the effect of the two fiscal variables on each other, one can notice that when current outlays increase public investment is strongly reduced, whereas the shock on investment does not produce the same effect on current outlays. As a consequence, the temporary increase in debt is larger in the latter case. This finding gives some support to the well-known argument that it is easier to reduce investment than current outlays; and to the related claim that in case of increases in investment, policymakers are eager to open the Pandora box, satisfying the claims for higher current expenditures. It needs to be stressed, nevertheless, that the resulting increase in the public debt to GDP ratio is only temporary.

Our estimation of the economy's response to a structural shock on public investment does not give information about the effects, if any, of the adoption of a "golden rule of public finance" in the UK. Moreover, with too-few data since 1998, the adoption date, it is not possible to split the sample in a pre- and a post-golden rule subsample, and to analyse them separately. To give at least a tentative assessment of the golden rule incidence we re-estimate the SVAR on a subsample excluding the years from 1998 onwards. We then gauge the differences between the IRFs of public investment on GDP. A significant difference is attributed to a change in the set of fiscal rules, while the direction of the change gives some information, albeit only suggestive, on the (possible) effects of adopting a golden rule.

In fact, excluding the years over which the 'Code for Fiscal Stability' has been implemented shows very interesting results, reported in figure 3. Focusing on a shock on public investment, it is shown that within the most appropriate ordering (public investment, first), public investment has a significant impact on real GDP on very short periods: over two quarters in the short run and 2 to 3 years after the shock occurred.

We interpret this result - the lower efficiency of public investment on output when the 'Code for Fiscal Stability' is removed from the sample - as a first, though rough, evidence of the positive impact on the UK economy of the application of the "golden rule of public finance" at the national level.

Now focusing on the shock on current outlays, it is shown that they have lost their positive and significant impact on real GDP in the short run, in comparison with the IRFs obtained on the full sample. In the mid and long-run however, current outlays still positively impinge on economic growth; responses are significant.

[INSERT FIGURE 3] 


\section{Robustness}

In the following, we assess the robustness of our results: public investment efficiency; to a lesser extent, current outlays efficiency; and the asymmetry in the interactions between fiscal variables depending on which one underwent a positive shock.

Before that, however, figure 4 reports the dynamic responses of public investment, current outlays, tax receipts and GDP to structural shocks on respectively public investment and current outlays (in this model debt, inflation and the interest rate are absent). Estimations were based on Blanchard and Perotti's methodology extended to a decomposition of public expenditures, following the steps described in Perotti $(2004)^{11}$.

\section{[INSERT FIGURE 4]}

The results replicate Perotti's (2004) estimations for the UK, although he also introduced inflation and interest rates in his model. First, public investment would have no discretionary impact on GDP: responses are not statistically significant. Since public investment is fully discretionary by definition when it is ordered first, with the exception of the possible impact of inflation on it, this means that public investment has no impact at all on UK GDP. Public investment would only impinge on other fiscal and tax variables. Second, current outlays would have a negative impact on GDP, except in the very short run, and would contradict textbook analyses. Both results - total inefficiency of public investment and negative effects of current outlays - are robust to a change in the ordering and to a change in the sample. Changing the ordering - with current outlays coming first and public investment second -or removing the golden rule years (1998 onwards) from the sample did not modify the impulse response functions ${ }^{12}$.

Drawing on these results however, public debt should have soared in the UK since 1997 after public investment had been increased. A look at the data of the National Statistics Institute does not testify for such a rise: between 1998 and 2001, net and gross public debt decreased in percentage of GDP and the rise which has happened since 2001 has left both ratios below their values of 1997 .

Although the impulse responses obtained with Perotti's identification seem at odds with the data, it enabled to check that the series we used in our extended framework are consistent with Perotti's. In this sense, our dataset is robust.

Specific robustness checks of our own results come. First, the ordering of fiscal variables in our SVAR model has been changed: it has been assumed that current outlays do not respond immediately to the structural shock on public investment, whereas the reverse is true for public investment. Results are reported in figure 5. In this setting, public investment is less efficient (as far as real GDP is concerned) than in the previous ordering: the immediate

${ }^{11}$ Estimations were implemented with variables expressed in first difference, hence stationary variables as in Blanchard and Perotti (2002). Impulse response functions reported on figure 4 are cumulated impulse responses and are therefore expressed in percentage points or percentage variations of, on the one hand, fiscal and tax variables, and, on the other hand, GDP.

${ }^{12}$ The corresponding figures are available from the authors upon request. 
rise in output is no longer significant (which is not completely unlikely) and its long-run rise is no longer statistically significant over the entire time span. The short run response of GDP may have been influenced by the reaction of the real interest rate: it is now increasing in the short-run, and significantly so. It remains to acknowledge that public investment has still a positive impact on real GDP around 5 years after the shock occurred. All in all, the significant positive impacts of public investment on economic growth on the entire time span are larger than their significant negative impacts.

As for the relative efficiency of current outlays in boosting economic growth, on the one hand, and the asymmetry between both fiscal variables on the other hand, they seem to be robust to the change in the ordering.

\section{[INSERT FIGURE 5]}

Figure 6 changes the ordering for the subsample excluding the years 1998-2005. The response of real GDP to public investment shocks when current outlays come first is barely significant. This reinforces our interpretation that the implementation of the golden rule represented a regime change. On the other hand, the asymmetry between fiscal variables seems fairly robust to the sample and ordering changes, although to a lesser extent with the second ordering on the subsample excluding the 'Code for Fiscal Stability'. In this situation, the immediate and short-run increases in current outlays following a structural shock on public investment are no longer significant.

\section{[INSERT FIGURE 6]}

Finally, we test the robustness of our results with respect to the elasticity values used in the identification procedure. The test took the form of Monte Carlo experiment. First, we computed for each elasticity the $5^{\text {th }}$ and $95^{\text {th }}$ percentiles, based on the standard error of our estimates. These values are reported in table 4. The bounds are quite wide, reflecting high standard errors. In 5 cases the $5^{\text {th }}$ and $95^{\text {th }}$ percentiles have different signs.

Table 4. Elasticity bounds

\begin{tabular}{cccc}
\hline \hline Variable & Value & 5th perc. & 95th perc. \\
\hline$\alpha_{\mathrm{gc}, \mathrm{y}}$ & -0.7341 & -1.0260 & -0.4422 \\
$\alpha_{\tau, \mathrm{y}}$ & -0.3010 & -1.0757 & 0.4737 \\
$\alpha_{\mathrm{b}, \pi}$ & -0.2699 & -0.4228 & -0.1170 \\
$\alpha_{\mathrm{b}, \mathrm{r}}$ & 0.0710 & -0.3612 & 0.5032 \\
$\alpha_{\mathrm{gi}, \pi}$ & 0.0013 & -0.0024 & 0.0050 \\
$\alpha_{\mathrm{gc}, \pi}$ & -0.0001 & -0.0008 & 0.0007 \\
$\alpha_{\tau, \pi}$ & 0.0003 & -0.0016 & 0.0023 \\
\hline \hline
\end{tabular}

We then performed 1000 draws of the seven elasticities from uniform distributions with bounds given by the percentiles. For each of these draws we estimated the system using the 
drawed elasticity values, and we computed the bounds of the impulse response functions through the standard boostrapping technique. We then recorded the $4^{\text {th }}, 12^{\text {th }}$ and $24^{\text {th }}$ values of the cumulated IRF of GDP after a public investment shock, corresponding to the short, medium and long term multipliers. We thus ended with a dataset of 1000 multiplier values, associated to elasticity values spanning the whole interval. Both the use of a uniform distribution, and the wide bounds of the elasticity values, add noise to the experiment, thus making the robustness test more significant. In fact, if the findings of the previous sections are confirmed in such extreme conditions, we can expect them to be even more robust once we limit the elasticity range to values closer to the actual estimated values.

\section{[INSERT FIGURE 7]}

Figure 7 reports the distribution of the multipliers. We considered them to be positive if both the upper and the lower bound of the cumulate IRF were positive, negative if the bounds were both negative, and not significant if the two bounds had opposite signs.

The first striking result is that no run gave a negative multiplier, no matter what the time horizon was. Whatever the combination of elasticity values, we obtained positive or no effects on GDP. The second element that emerges from the experiment is that results of section 4 are substantially confirmed: The positive effects of public investment appear in the long run $(72 \%$ of the runs), while in the short run we have no significant effect two thirds of the time. It is interesting to remark that in all of our simulations, we observe no significant effect of public investment in the medium run (12 quarters, or 3 years).

\section{[INSERT FIGURE 8]}

A similar picture emerges from figure 8, where we plot the average value of the multiplier over the 1000 runs, together with its bounds. We can see that the average short term effect is positive but not significant, the medium term effect is negative but also not significant, and the only significant effect is the long run positive effect.

Also noteworthy, the long run outcome of a shock gives a reasonable value: a 1percentage point of GDP increase in public investment, decreasing along an AR process, produces an average cumulative rise of GDP of $25 \%$ in the long run.

Overall, the robustness checks confirm the argument of this paper. Public investment has no strong effects in the short-medium run, but it affects growth in the long run. This result is conform to the theoretical intuition, and emerges in a framework in which long run phenomena are properly accounted for.

\section{Conclusion}

Different tests have been performed to assess the incidence of public investment on key macroeconomic variables: fiscal and tax variables, public debt, inflation rate, interest rate, and real GDP. The introduction of debt is coherent with the long term model structure that we deem necessary to study the effects of investment. We argue that in the UK context, as well as in the more general context of studying the application of the golden rule of public finance, public debt cannot be ruled out. On the one hand, by the exclusion of public debt, we 
consistently replicate Perotti's (2004) results on the UK economy, in spite of a slightly different specification. On the other hand, we showed that incorporating public debt in the empirical analysis improved the results.

Four important findings have emerged from our study:

- Public investment in the UK has positive and permanent effects on real GDP, i.e. public investment is productive;

- Current outlays are also productive, thus eliminating the puzzle that emerged from Perotti (2004)'s specification.

- There is evidence that a change has occurred since the 'Code for Fiscal Stability' has been implemented: public investment was less efficient before that period;

- There is evidence that it exists an asymmetry in the interactions between current outlays and public investment, depending on which one has undergone a positive shock: catching-up of current outlays occurs when public investment is increased.

The distinction between current and capital spending which lies at the heart of the "golden rule of public finance" may be worth being emphasized in the European context: removing the bias against public capital spending as in the UK case would shift attention from a mere quantitative target (one of the most controversial characteristics of the Stability and Growth Pact) to the quality of public finance. Moreover, in the context of the Lisbon strategy stressing the development of an innovative area, public capital may play an important role through two additional channels: first, public investment provides public goods like transport infrastructures which benefit users and directly or indirectly improve total factor productivity; second, public investment also raises overall welfare when it participates in the protection of environment or enhances fairness in resource distribution.

\section{References}

Afonso A., L. Schuknecht and V. Tanzi (2006), "Public sector efficiency, evidence for new EU member states and emerging markets”, ECB Working Paper no.581, January.

Aghion Ph. and P. Howitt (1998), Endogenous Growth Theory, The MIT Press.

Aschauer D.A. (1989a), "Is Public Expenditure Productive?", Journal of Monetary Economics, vol.23, no.2, pp. 177-200.

Aschauer D.A. (1989b), "Public Investment and Productivity Growth in the Group of Seven", Journal of Economic Perspectives, no.13, pp. 17-25.

Bajo-Rubio O. and S. Sosvilla-Rivero (1993), "Does Public Capital Affect Private Sector Performance? An Analysis of the Spanish Case, 1964-88”, Economic Modelling, 10(3), July.

Balassone F. and D. Franco (2000), "Public Investment, the Stability Pact and the 'Golden Rule"”, Fiscal Studies, vol.21, no.2..

Barro R.J. and X. Sala-I-Martin (1995), Economic Growth, McGraw-Hill. 
Berndt E.R. and B. Hansson (1992), "Measuring the Contribution of Public Infrastructure Capital in Sweden", Scandinavian Journal of Economics, 94.

Blanchard O.J. (1985), "Debt, deficits, and finite horizons", Journal of Political Economy, 93(2), April.

Blanchard O.J. and F. Giavazzi (2003), "Improving the SGP through a Proper Accounting of Public Investment", European Economic Perspectives newsletter, CEPR, no.1, February.

Blanchard O.J. and R. Perotti (2002), "An Empirical Characterization of the Dynamic Effects of Changes in Government Spending and Taxes on Output", Quarterly Journal of Economics, 117(4), pp. 1329-68.

Bleaney M., N. Gemmel and R. Kneller (2001), "Testing Endogenous Growth Model: Public Expenditure, Taxation and Growth over the Long Run", Canadian Journal of Economics, vol. 34, no.1.

Buti M., S.C.W. Eijffinger and D. Franco (2003), "Revisiting the SGP: Grand Design or Internal Adjustment?", CEPR Discussion Paper, no.3692, January.

Buiter W.H. (2001), "Notes on 'A Code for Fiscal Stability", Oxford Economic Papers, vol.53, no.1.

Christiano L.J., M. Eichenbaum and C.L. Evans (1999), "Monetary policy shocks: what have we learned and to what end?, in J.B. Taylor and M. Woodford (eds.), Handbook of Macroeconomics, Elsevier.

Clarida R.H. (1993), "International Capital Mobility, Public Investment and Economic Growth", NBER Working Paper, no.4506.

Creel J. and H. Sterdyniak (2002), "The fiscal theory of the price level and sluggish inflation: how important shall the wealth effect be?", Working Paper, OFCE, no.2002-01.

Dessus R. and Herrera S. (1996), «Le rôle du capital public dans la croissance des pays en développement au cours des années $80 »$, Centre de développement, OECD, Technical Document no.115.

EC (2003), "Public Finances in EMU 2003", European Economy, no.3, European Commission.

Evans P. and Karras G. (1994), "Is Government Capital Productive? Evidence from a Panel of Seven Countries", Journal of Macroeconomics, 16, 271-279.

Fitoussi J.-P. and J. Creel (2002), How to Reform the ECB, Center for European Reform, London, October.

Garcia-Milà T. and T.J. McGuire (1992), "The contribution of publicly provided inputs to states' economies”, Regional Science and Urban Economics, no.22, pp. 229-241. 
Gong G., A. Greiner and W. Semmler (2004), "Estimating an endogenous growth model with public capital and government borrowing: US and Germany 1960-1995”, Computational Economics, 23(1), February.

Heijdra B.J. and L. Meijdam (2002), "Public Investment and Intergenerational Distribution”, Journal of Economic Dynamics and Control, vol.26, no.5, May.

HM Treasury (2002), Core Debt: an Approach to Monitoring the Sustainable Investment Rule, April.

Kneller R., M.F. Bleaney and N. Gemmell (1999), "Fiscal policy and growth: evidence from OECD countries", Journal of Public Economics, 74(2), November.

Knight M., N. Loayza and D. Villanueva (1993), "Testing the Neoclassical Theory of Economic Growth”, IMF Staff Papers, vol.40, pp. 512-541.

Leeper, E. M. (1991), “Equilibria under 'Active' and 'Passive' Monetary and Fiscal Policies”, Journal of Monetary Economics, 27(1), pp. 129-47

Leith C. and S. Wren-Lewis (2000), "Interactions between Monetary and Fiscal Policy Rules”, Economic Journal, 110(462).

Ligthart J.E. (2000), "Public Capital and Output Growth in Portugal: An Empirical Analysis", IMF Working Paper, no.11.

Mc Millin W.D. and D.J. Smyth (1994), "A multivariate time series analysis of the United States aggregate production function", Empirical Economics, vol.19, pp. 659-673.

Merriman D. (1990), "Public Capital and Regional Output: Another Look at some Japanese and American Data”, Regional Science and Urban Economics, vol.20, pp. 437-458.

Musgrave R. (1966), "Principles of Budget Determination", in H. Cameron and W. Henderson (eds.), Public Finance: Selected Readings, Random House.

Otto G.D. and G.M. Voss (1994), "Public Capital and Private Sector Productivity", Economic Record, 70(209), June.

Otto G.D and G.M. Voss (1996), "Public Capital and Private Production in Australia", Southern Eastern Journal, vol.62, pp. 723-738.

Otto G.D and G.M. Voss (2002), "Public and Private Investment in the United States and Canada", Economic Modelling, vol.19, no.4, pp. 641-664.

Perotti R. (2004), "Public investment: Another (Different) Look", IGIER Working Paper no.277, Bocconi University, December.

Ram R. and D. Ramsey (1989), “Government capital and private output in the United States", Economics Letters, 30(3), September.

Ratner J.B. (1983), "Government Capital and the Production Function for U.S. Private Output", Economic Letters, vol.13, pp. 213-217. 
Sawyer M. (2006), "Economic Policy in the UK under the new Labour: the end of boom and bust?”, mimeo, University of Leeds, June.

Sims C. (1980), "Macroeconomics and Reality”, Econometrica, 48(1), January, pp. 1-48.

Sims C.A., J.H. Stock and M.W. Watson (1990), "Inference in Linear Time Series Models with Some Unit Roots", Econometrica, 58(1), January, pp.113-44.

Stock, J. H. and M. W. Watson (2001), "Vector Autoregressions", Journal of Economic Perspectives, 15(4), pp. 101-15.

Sturm J.E. and J. De Haan (1995), "Is Public Expenditure Really Productive? New Evidence for the U.S. and the Netherlands", Economic Modelling, vol.12, pp. 60-72.

Sturm J.E., J.P.A.M. Jacobs and P. Groote (1999), "Output effects of Infrastructure Investment in the Netherlands 1853-1913”, Journal of Macroeconomics, 21(2).

Vijverberg W.P.M., C.P.C. Vijverberg and J.L. Gamble (1997), "Public capital and private productivity", Review of Economics and Statistics, 79(2), May.

Wylie P.J. (1996), "Infrastructure and Canadian Economic Growth", Canadian Business Economics, 3(2), Winter.

Yaari M. (1965), "Uncertain lifetime, life insurance, and the theory of the consumer", Review of Economic Studies, 32, April.

\section{Appendix: Stability conditions for the model of section 3.1}

If $d x$ is the time derivative of variable $x$, i.e. $d x(t) / d t$, the full model can be rewritten under matrix algebra form,

$$
\left[\begin{array}{l}
d b^{\prime}(t) \\
d \pi^{\prime}(t)
\end{array}\right]=\mathbf{A}\left[\begin{array}{l}
b^{\prime}(t) \\
\pi^{\prime}(t)
\end{array}\right],
$$

where $\mathbf{A}=\left[\begin{array}{cc}1+\bar{r}-h+\frac{\theta \bar{b}(\varphi-h)}{1+\delta \theta} & \frac{\bar{b} \mu}{1+\delta \theta} \\ \frac{v(\varphi-h)}{1+\delta \theta} & -\frac{\delta \mu \nu}{1+\delta \theta}\end{array}\right]$; a primed variable denotes deviations from the steady state and a variable with an upper bar denotes steady state value.

Under rational expectations, the forward-looking Phillips curve requires that $v<0$. A sufficient stability condition of the model is that $\operatorname{det} \mathbf{A}<0$. This is possible under the usual Leeper (1991)'s conditions. The model is locally-stable under two different features of monetary and fiscal policies: either both policies react toughly to respective deviations from their objectives $\quad\left(\mu>0\right.$ and $\left.h>\frac{\delta(1+\bar{r})+\bar{b} \varphi}{\delta+\bar{b}}\right) ; \quad$ or both policies react mildly $\left(\mu<0\right.$ and $\left.h<\frac{\delta(1+\bar{r})+\bar{b} \varphi}{\delta+\bar{b}}\right)$, with the real interest rate decreasing after an inflationary shock. 
Under adaptive expectations, the backward-looking Phillips curve requires that $v>0$. With two pre-determined variables, stability conditions require that $\operatorname{det} \mathbf{A}>0$ and $\operatorname{tr} \mathbf{A}<0$. If $\mu>0$, the condition on the reaction of fiscal policy towards deviations of public debt is: $h>\frac{\delta(1+\bar{r})+\bar{b} \varphi}{\delta+\bar{b}}$ and $\mathrm{h}>\frac{(1+\delta \theta)(1+\overline{\mathrm{r}})+\theta \bar{b} \varphi-\delta \mu \nu}{1+(\delta+\bar{b}) \theta}$. If $\mu<0$, stability requires that the government does not react too much but also not too little to public debt deviations, $h<\frac{\delta(1+\bar{r})+\bar{b} \varphi}{\delta+\bar{b}}$ and $\mathrm{h}>\frac{(1+\delta \theta)(1+\overline{\mathrm{r}})+\theta \bar{b} \varphi-\delta \mu \nu}{1+(\delta+\bar{b}) \theta}$ : a sufficient but not too strong wealth effect stabilises the whole economy.

\section{Figures}

Figure 1. UK government primary balance and government fixed gross capital formation (in percentage points of GDP) source: OECD

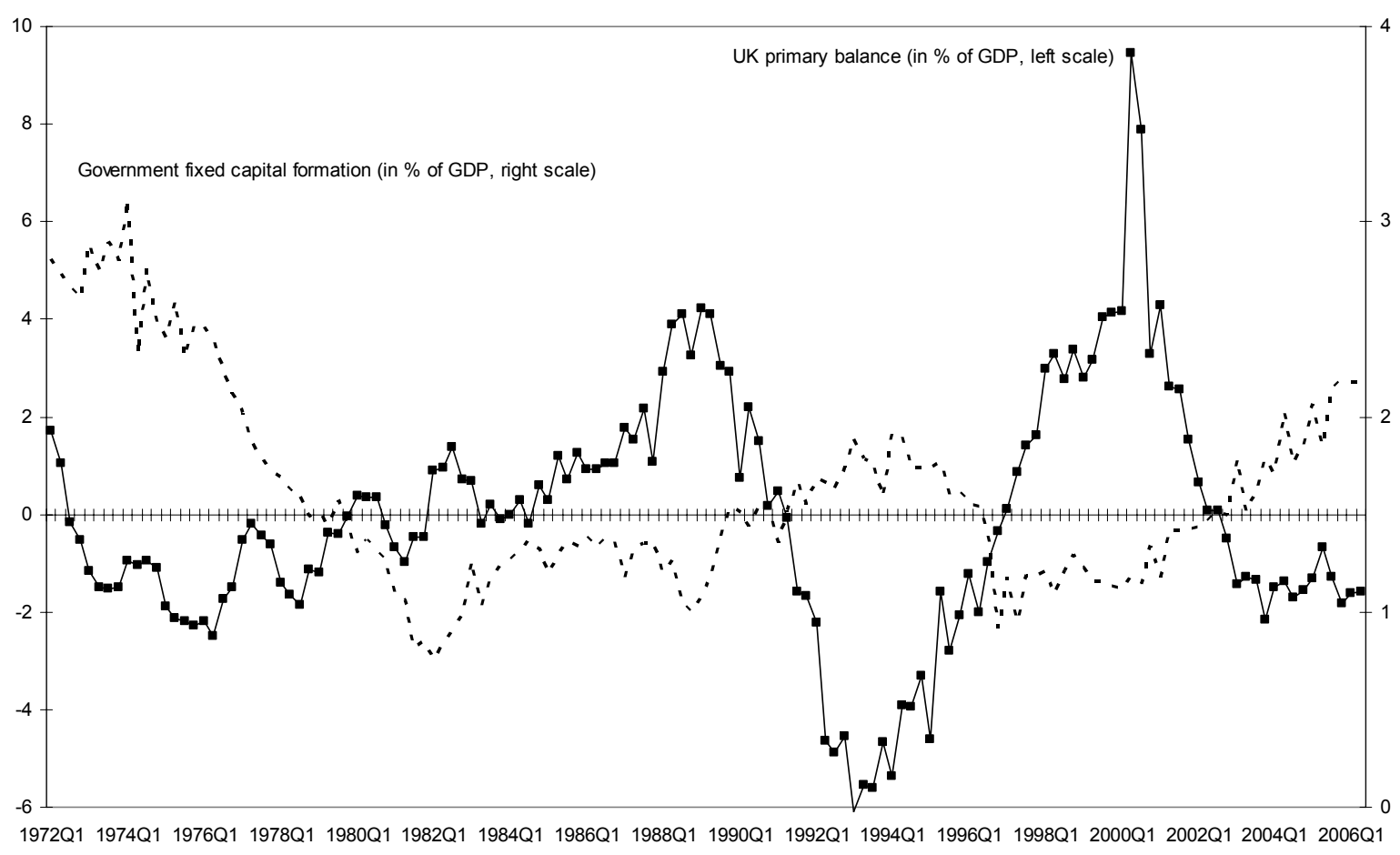


Figure 2. Full sample, first ordering, UK

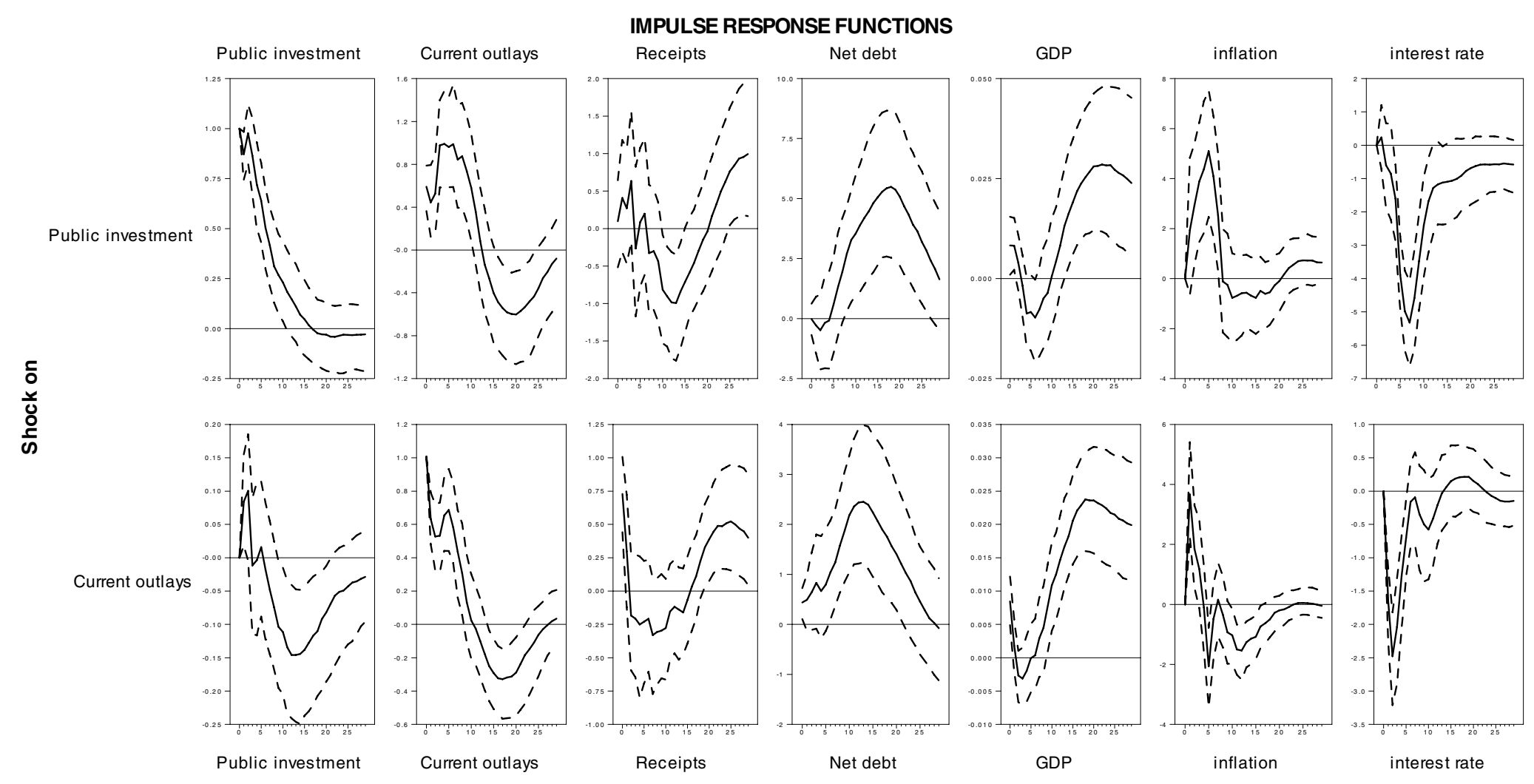

Note. Figures read like this: for instance, on the first line of graphs, a 1-percentage point of GDP increase in public investment, decreasing along an AR process, produces a rise of about 5 percentage points of GDP of public debt and a rise of about 2\% of GDP above their respective initial values 15 quarters after the shock. Inflation rises by 5 percentage points above its initial value 5 quarters after the shock. 
Figure 3. Short sample, excluding the years of the Code for Fiscal Stability, first ordering, UK

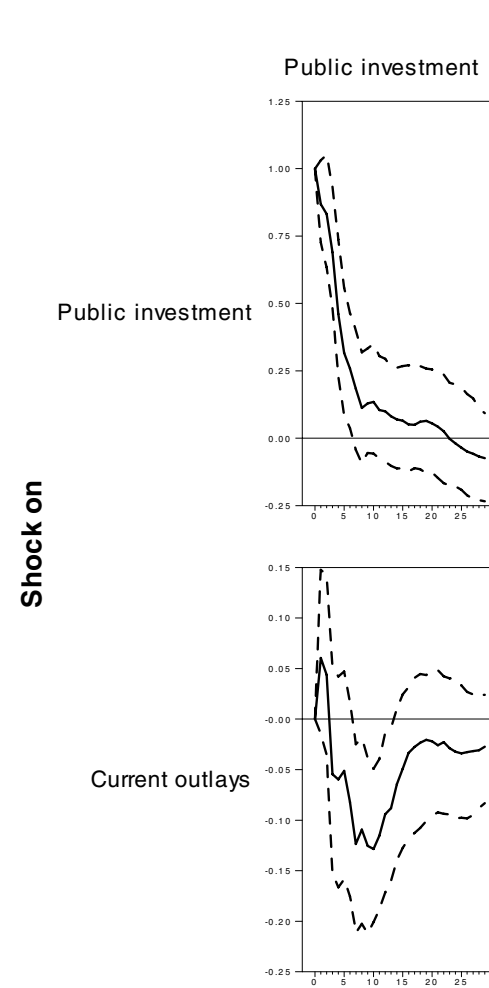

Public investment
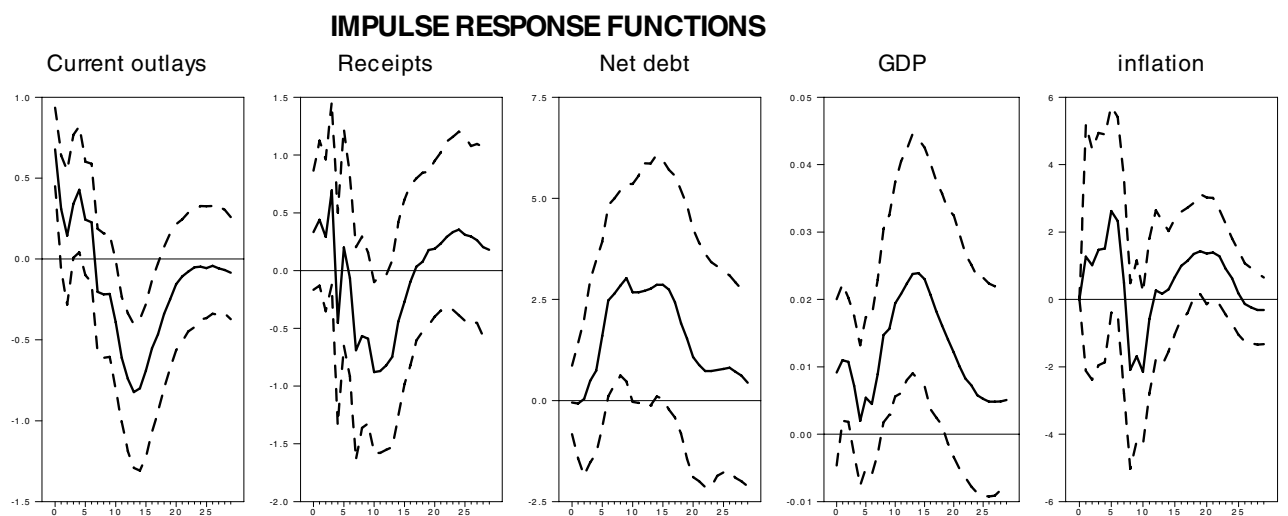

interest rate

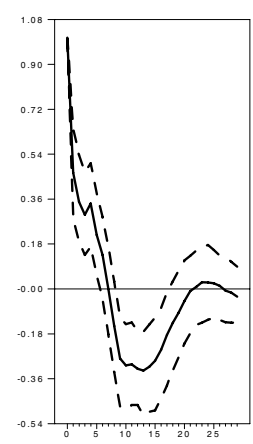

Current outlays

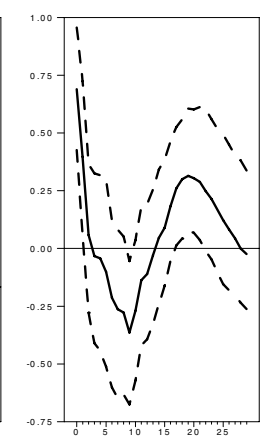

Receipts

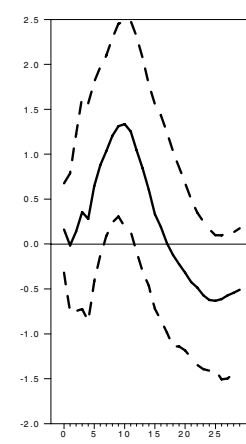

Net debt

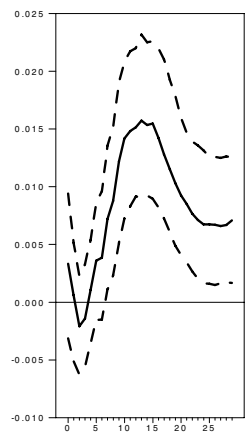

GDP

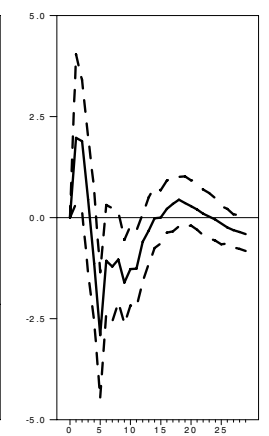

inflation
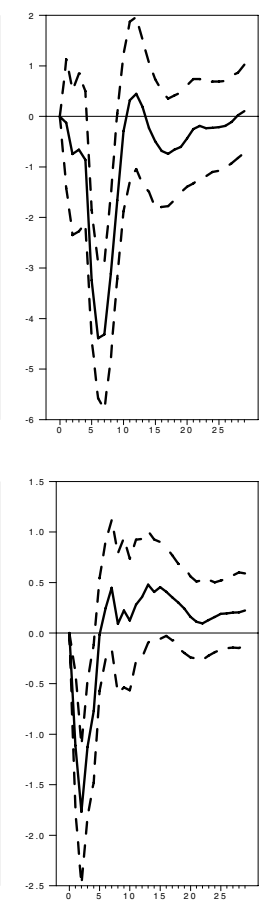

interest rate 
Figure 4. Blanchard \& Perotti's framework

with a decomposition of government outlays, UK
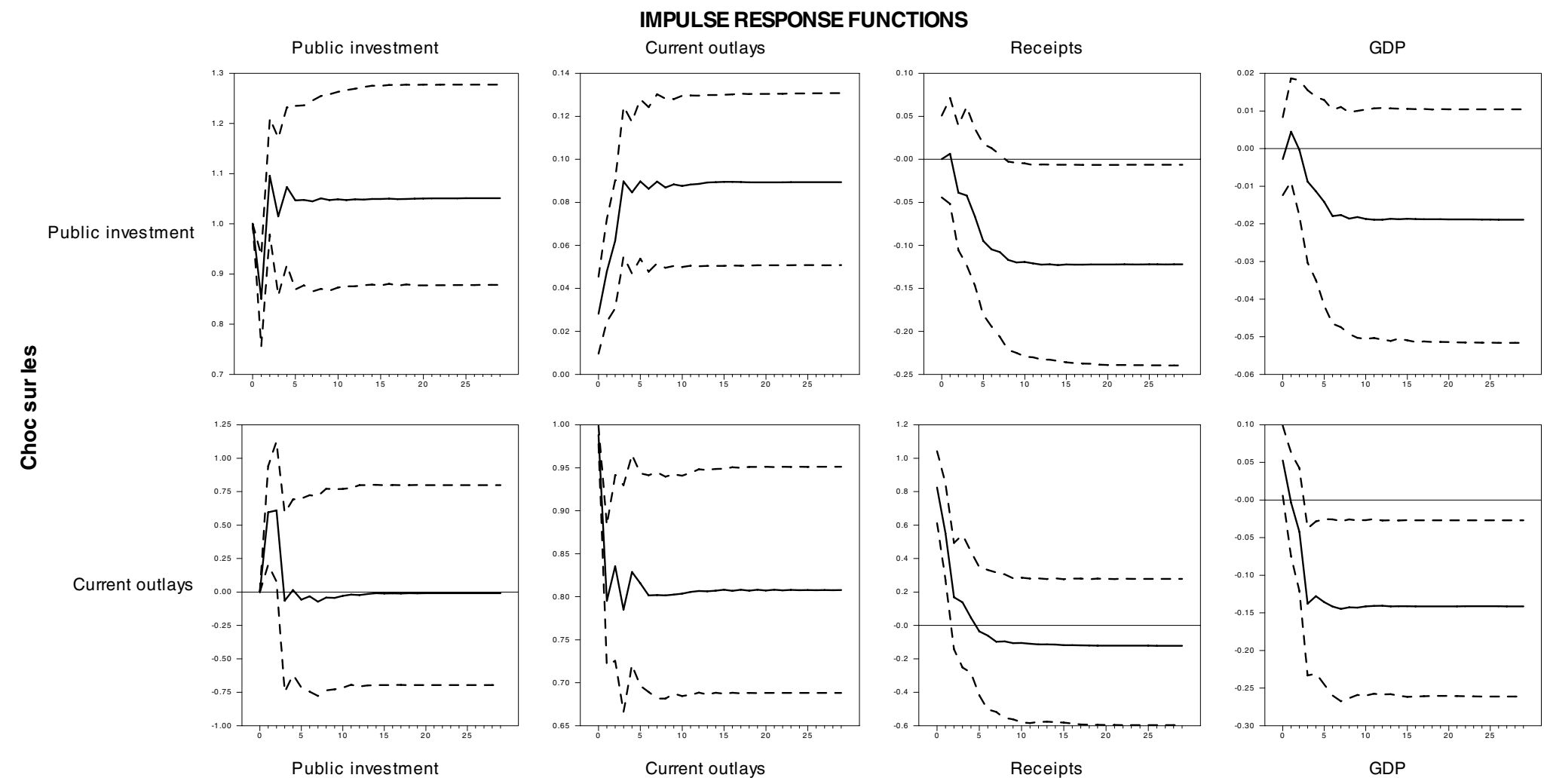

Receipts

GDP 
Figure 5. Full sample, second ordering, UK

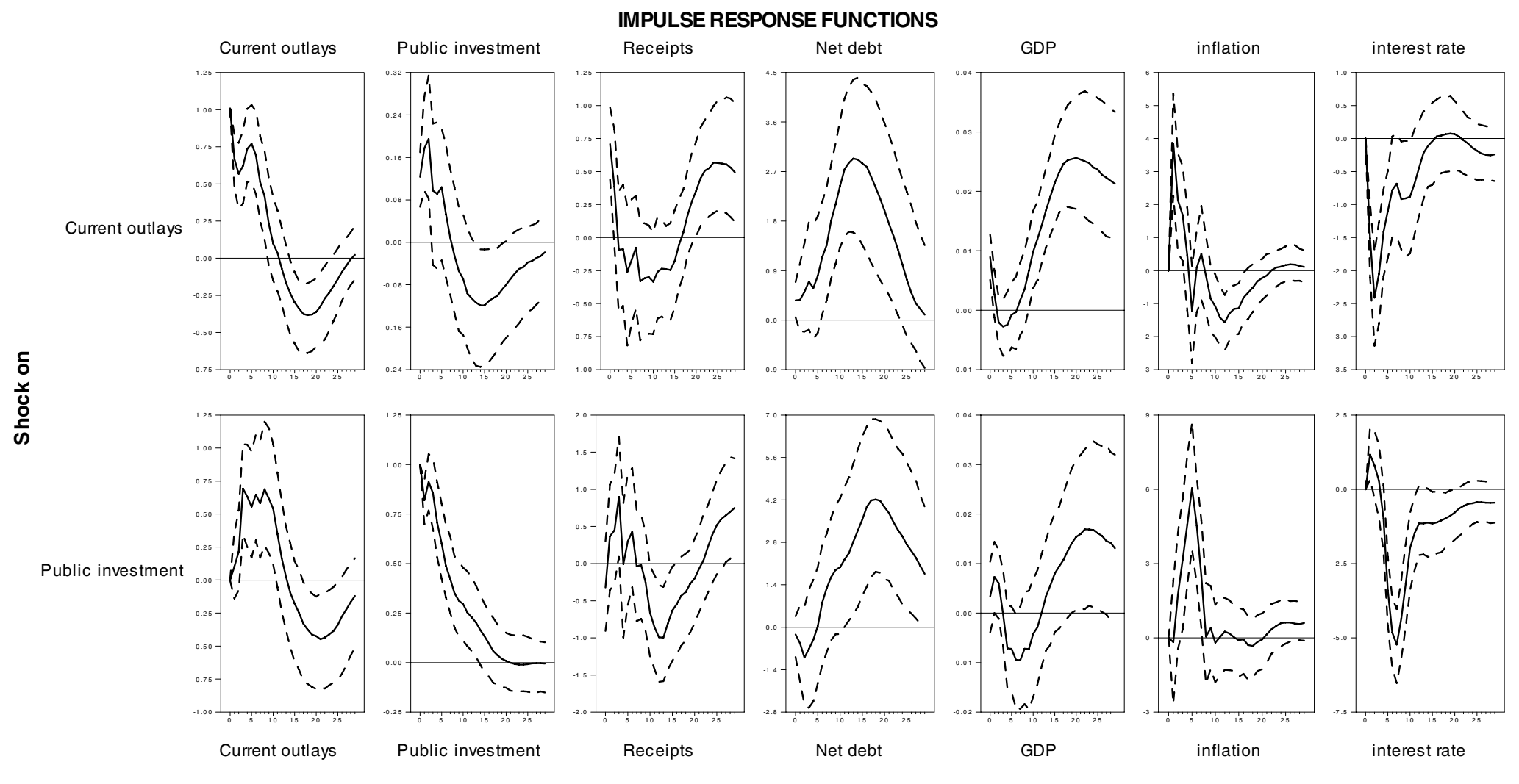


Figure 6. Short sample, excluding the years of the Code on Fiscal Stability, second ordering, UK

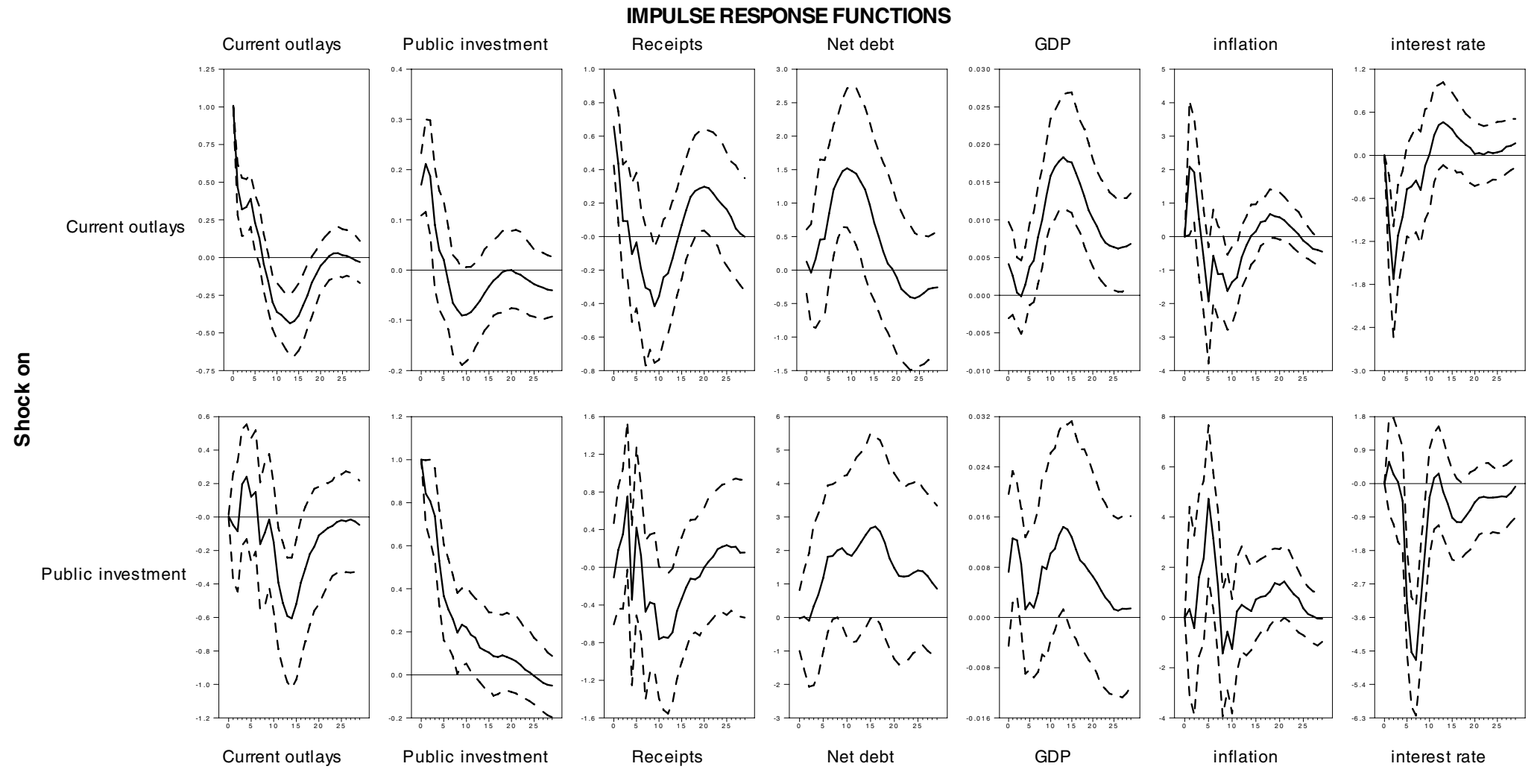


Figure 7. Monte Carlo Robustness Check.

Distribution of Public Investment Multipliers

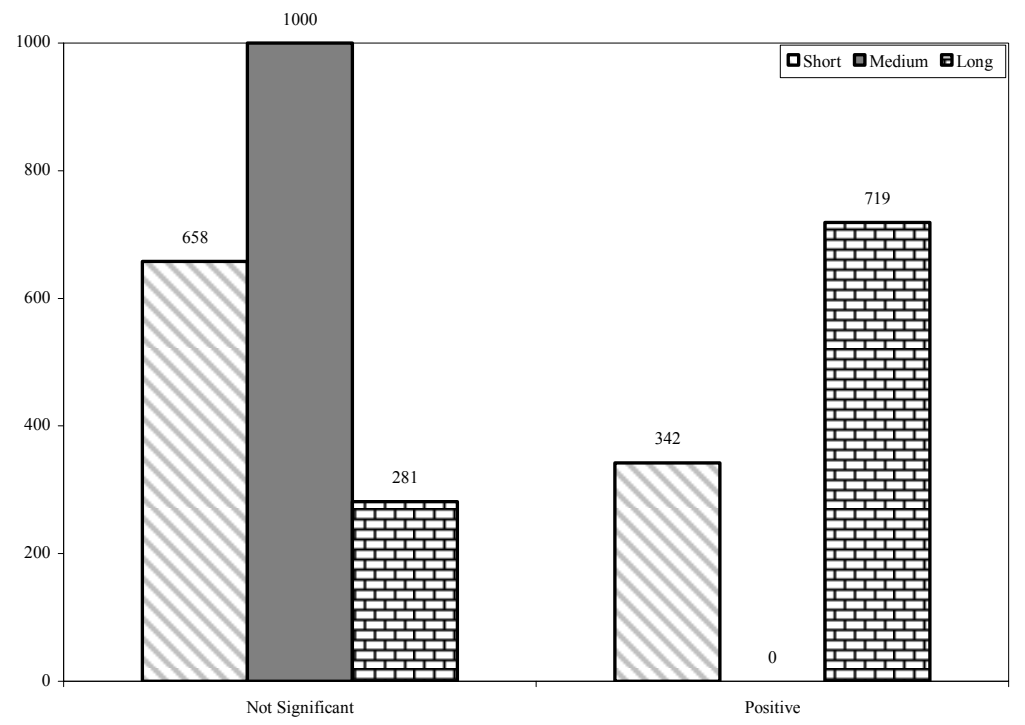

Figure 8. Monte Carlo Robustness Check. Average Value of the Public Investment Multiplier and Bounds

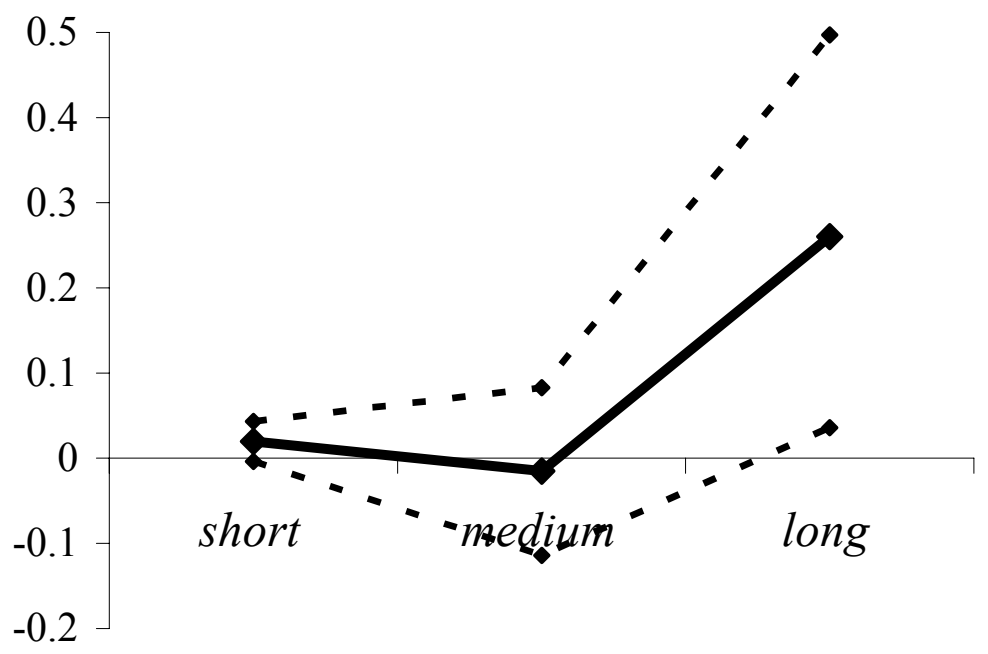

Note. Figures read like this: a 1-percentage point of GDP increase in public investment, decreasing along an AR process, produces an average cumulative rise of GDP of $25 \%$ in the long run. 